\title{
Experimental Investigation of the Early Stage of Precipitation on Binary Al-Li, Al-Cu Alloys and Ternary Al-Li-Cu Alloys by Means of Atom Probe Tomography
}

\author{
Muna Khushaim ${ }^{1,2}$, Torben Boll ${ }^{3}$ \\ ${ }^{1}$ Department of Physics, Taibah University, Medina, KSA \\ ${ }^{2}$ Physical Sciences and Engineering Division, King Abdullah University of Science and Technology (KAUST), Thuwal, KSA \\ ${ }^{3}$ Deportment of Applied Physics, Chalmers University of Technology, Goteborg, Sweden \\ Email: Muna.Khushaim@kaust.edu.sa
}

How to cite this paper: Khushaim, M. and Boll, T. (2016) Experimental Investigation of the Early Stage of Precipitation on Binary Al-Li, Al-Cu Alloys and Ternary Al-Li-Cu Alloys by Means of Atom Probe Tomography. Open Journal of Metal, 6, 25-44.

http://dx.doi.org/10.4236/ojmetal.2016.62003

Received: August 1, 2016

Accepted: September 25, 2016

Published: September 28, 2016

Copyright $\odot 2016$ by authors and Scientific Research Publishing Inc. This work is licensed under the Creative Commons Attribution International License (CC BY 4.0).

http://creativecommons.org/licenses/by/4.0/ (c) (i) Open Access

\begin{abstract}
Aluminum-based alloys play a key role in modern engineering and are widely used in construction components in aircraft, automobiles and other means of transportation due to their light weight and superior mechanical properties. Introduction of different nano-structure features can improve the service and the physical properties of such alloys. An improvement of an Al-based alloy has been performed based on the understanding of the relationships among compositions, processing, microstructural characteristics and properties. Knowledge of the decomposition process of the microstructure during the precipitation reaction is particularly important for future technical developments. The objective of this study is to investigate the nano-scale chemical composition in the $\mathrm{Al}-\mathrm{Cu}, \mathrm{Al}-\mathrm{Li}$ and $\mathrm{Al}-\mathrm{Li}-\mathrm{Cu}$ alloys during the early stage of the precipitation sequence and to describe whether this compositional difference correlates with variations in the observed precipitation kinetics. Investigation of the fine scale segregation effects of dilute solutes in aluminum alloys which were experienced different heat treatments by using atom probe tomography has been achieved. The results show that an $\mathrm{Al}-1.7$ at.\% $\mathrm{Cu}$ alloy requires a long ageing time of approximately $8 \mathrm{~h}$ at $160^{\circ} \mathrm{C}$ to allow the diffusion of $\mathrm{Cu}$ atoms into $\mathrm{Al}$ matrix. For the Al-8.2 at.\% Li alloy, a combination of both the natural ageing condition ( $48 \mathrm{~h}$ at room temperature) and a short artificial ageing condition $\left(5 \mathrm{~min}\right.$ at $160^{\circ} \mathrm{C}$ ) induces increasing on the number density of the Li clusters and hence increase number of precipitated particles. Applying this combination of natural ageing and short artificial ageing conditions onto the ternary $\mathrm{Al}-4$ at.\% $\mathrm{Li}-1.7$ at.\% $\mathrm{Cu}$ alloy induces the formation of a $\mathrm{Cu}$-rich phase. Increasing the Li content in the ternary alloy up to 8
\end{abstract}


at.\% and increasing the ageing time to $30 \mathrm{~min}$ resulted in the precipitation processes ending with $\delta^{\prime}$ particles. Thus the results contribute to the understanding of Al-alloy design.

\section{Keywords}

Phase Decomposition, Atom Probe Tomography, Early Stage of Precipitation

\section{Introduction}

Aluminum of high purity in an annealed condition has a low strength near $10 \mathrm{MPa}$ [1]. Generally, pure metals are strengthened by the introduction of obstacles (i.e., any inhomogeneity) in their microstructures to pin dislocations. Thus, the introduction of solute atoms into the $\mathrm{Al}$ matrix is considered to be an important method to improve conventional $\mathrm{Al}$ alloys. Adding solute atoms to a solid solution in the solvent atom's lattice typically produces an alloy that is stronger than pure $\mathrm{Al}$ due to the differences in the radius, modulus and valance between the $\mathrm{Al}$ matrix and the solute atoms [2]. In general, the solute must have an appreciable solid solubility in the matrix at the annealing temperature, and has also to remain in the solid solution after slowly cooling and must not be removed by reacting with other elements in the alloy [1]. Additions of $\mathrm{Li}$ and/or $\mathrm{Cu}$ to $\mathrm{Al}$ have been identified as an efficient strategy to improve the strength in age-hardenable or heat-treatable $\mathrm{Al}$ alloys via the precipitation hardening phenomenon.

The formation of precipitates, nano-scale structure features which are formed during the fine-scale segregation of dilute solutes, in a metal's microstructure during ageing occurs in many different ways. After quenching from a solid solution, the microstructure of $\mathrm{Al}$ alloys typically contains regions of solute segregation or solute-atom clusters. These clusters gradually transform into semi-coherent and non-coherent second-phase particles during artificial ageing [2]. The size, shape, volume fraction and coherency of the second phase precipitates determine the precipitation hardening of an alloy. These required parameters depend on the ageing temperature and ageing time. Thus, investigation of the precipitation kinetics in $\mathrm{Al}$ alloy is important.

The scale of the microstructures in modern metallic materials is becoming increasingly smaller [3]. A discussion of microstructures at such a small dimension is typically based on crystallographic structures and chemical characteristics relevant to the structure. However, this type of discussion was not possible until the development of more advanced tools, such as transmission electron microscopy (TEM) and electron energy loss spectroscopy (EELS). However, all of these advanced techniques have limitations when analyzing nano-scale particles embedded in a matrix phase. The atom probe tomography (APT) technique, particularly in its current form, has a truly quantitative analytical capability to characterize nanometer-scale particles in a metallic system. Thus, it has been used to investigate nano-scale microstructural evolution for bi- 
nary $\mathrm{Al}-\mathrm{Cu}, \mathrm{Al}-\mathrm{Li}$ alloys and ternary $\mathrm{Al}-\mathrm{Li}-\mathrm{Cu}$ alloys at the early stage of decomposition.

The binary Al-Cu alloy is a well-studied precipitation system and forms the basis for a wide range of age-hardenable alloys that are technologically important. The model for describing the fundamentals of the precipitation sequence in the binary $\mathrm{Al}-\mathrm{Cu}$ alloy is [4]:

$$
\mathrm{GPI} \rightarrow \operatorname{GPII}\left(\theta^{\prime \prime}\right) \rightarrow \theta^{\prime} \rightarrow \theta
$$

The presence of $\mathrm{Cu}$-rich groups of atoms that were coherent with the $\{100\}$ atomic planes of the $\mathrm{Al}$ matrix has been discovered by Guinier and Perston [5]. Based on this, GPI and GPII are the coherent zones, which were named by their discoveries, i.e. Guinier and Perston. Later, studies showed that the GPI zone could be described as consisting of a single layer of $\mathrm{Cu}$ atom on the $\{001\} \mathrm{Al}$ planes, while the structural model of the GPII zone consists of two $\mathrm{Cu}\{002\}$ layers separated by three $\mathrm{Al}$ planes with the stoichiometry of [6] [7]. The metastable $\theta^{\prime}$ phase, is considered to be the primary strengthening phase, has a body-centered tetragonal crystal structure with the stoichiometry $\mathrm{Al}_{2} \mathrm{Cu}$ [8]. The precipitation sequence ends with the transformation of $\theta^{\prime}$ into the incoherent equilibrium $\theta$ phase $\left(\mathrm{Al}_{2} \mathrm{Cu}\right)$, which exhibits a tetragonal $C 16$ crystal structure.

The increasing use of Al-Cu alloys in commercial applications requires further studies of the properties of the system and in particular the primary strength phase (i.e., the $\theta^{\prime}$ phase). Relatively speaking, little is known about the compositional evolution of $\theta^{\prime}$ compared to its properties. There are few studies in the literature on the presence of small, disordered clusters of atoms prior to the formation of GP zones. Because commercial optimization tools rely upon accurate predictions of alloy microstructures as functions of heat-treatment conditions, it is important to investigate the influence of nano-scale chemical compositions on precipitation kinetics.

The early stages of phase decomposition of Al-Li binary alloys have been reported to be a subject of controversy [9]. Earlier studies by electron microscopy [10] [11] reported that the precipitation process of this system is quite simple:

$$
\mathrm{SSS} \rightarrow \delta^{\prime} \rightarrow \delta
$$

where SSS is an abbreviation of "super saturated solid" solution, $\delta^{\prime}$ is the $\mathrm{Al}_{3} \mathrm{Li}$ metastable phase with an structure, and $\delta$ is a stable phase with a $B 32$ structure. The TEM images of the as-quenched alloy show a high density of small $\delta^{\prime}$ precipitate particles; thus, it was found that the $\delta^{\prime}$ phase formed during quenching after the solution heat treatment [9]. Controversy on the phase decomposition of this system arose from the presence of disordered GP zones prior to the precipitation of the phase or not. On the other hand, a selected area diffraction pattern (SADP) from the as-quenched alloys showed strong $L 1_{2}$ ordering spots, which suggest the presence of $\delta^{\prime}$ particles from the beginning of the process [10] [11]. Khachaturyan et al. [12] suggested different transformation paths in this alloy system and investigated transformation from a solid solution to an $L 1_{2}$ phase using the mean field approximation; they suggested that a solid solution decomposes into an ordered structure without any composition change (i.e., congruent 
ordering) and that this ordered structure is further separated into Li-rich, ordered $\delta^{\prime}$ regions and Li-depleted, disordered regions via a spinodal decomposition. There are two models of congruent ordering: Nucleation and growth of the ordered domains, and spontaneous homogeneous ordering. In either case, the quenched SSS should order congruently before the spinodal decomposition proceeds. To prove this transformation path, it is important to show the presence of the congruent order before the compositional fluctuation appears. Different studies have investigated this phenomenon [12]-[14]. The primary conclusion that has been drawn from all of these studies is that the kinetics of decomposition are too rapid to be followed by high-resolution techniques such as high-resolution transmission electron microscopy HRTEM. Thus, our objective in this study is to examine the microstructure at the early stage of decomposition in an $\mathrm{Al}-\mathrm{Li}$ alloy to determine the presence of atom clustering or fine segregation. Because a subtle variation in the heat-treatment condition can exert considerable influence over the volume fraction of already formed $\delta^{\prime}$ particles during subsequent precipitation reactions, APT analyses were performed to investigate the precipitation behavior after applying the heat treatment conditions in Table 1 .

Al-Li-Cu alloys typically exhibit high strengths and good mechanical properties compared to Al-Li alloys. Due to their superior mechanical properties, these alloys are typically used in applications where strength is the limiting factor in the design. The experimental data for $\mathrm{Al}-\mathrm{Li}-\mathrm{Cu}$ systems is primarily concentrated in the $\mathrm{Al}$ corner of the phase diagram [15]. The first systematic study of the phase equilibria in Al-Li-Cu systems was performed by Hardy and Silcock [16], who reported on a total of six ternary solid phases. The solidus and solvus temperatures were determined for different ternary Al-Li-Cu alloys with different compositions [17]. The thermodynamic properties of the phases in this system were studied by different researchers [18] [19]. The $\mathrm{T}_{1}\left(\mathrm{Al}_{2} \mathrm{LiCu}\right)$ phase is the primary strengthening phase in $\mathrm{Al}-\mathrm{Li}-\mathrm{Cu}$ alloys and is formed congruently near $695^{\circ} \mathrm{C}$ [20]. The hexagonal crystal structure of the $T_{1}$ phase was first proposed by Hardy and Silcock [16]. The $\mathrm{T}_{1}$ phase formation was assumed to occur via direct nucleation and growth from a saturated $\mathrm{Al}$ solid solution following a stacking fault mechanism [21]. Refinement of the hexagonal structure of $\mathrm{Al}_{2} \mathrm{LiCu}$ was achieved using single-crystal X-ray diffraction by Van Sammleen [22]. Semi-coherent and incoherent precipitation of the $T_{1}$ phase was detected and reported in reference [23] without any indication of the presence of quenched vacancies.

The determination of precipitation behavior is typically performed using an advanced technique such as APT for specimens that have experienced different conditions.

Table 1. Names and descriptions of the three applied aging conditions.

\begin{tabular}{cc}
\hline Name of the heat treatment condition & Corresponding aging condition \\
\hline First stage $(1 \mathrm{~S})$ & Fully annealed at room temperature (naturally aging) \\
Second stage $(2 \mathrm{~S})$ & Annealed at $160^{\circ} \mathrm{C}$ for $5 \mathrm{~min}$ (artificially aging) \\
Third stage (3S) & Naturally ageing at room temperature for $48 \mathrm{~h}$ and \\
& artificially aging at $160^{\circ} \mathrm{C}$ for 5 min \\
\hline
\end{tabular}


However, it is difficult to ensure an accurate following of the precipitation sequence due to the complexity caused by the nucleation stage. The competition between different phases in the binary and ternary system increases the challenge for any phase analysis. Co-precipitation is usually dominated by the phase that can minimize the interphase boundary energy and form at defects that can assist in the reduction of the nucleation energy barrier [24]. The simultaneous formation of different phases usually occurs when they are disparate, preferred sites; then, the competition would be for solutes that are necessary for growth; if a phase is metastable, it would dissolve during competitive growth and at the same time, the more stable phase would continue growing. Thus, it is necessary to follow precipitation sequence in the binary $\mathrm{Al}-\mathrm{Cu}, \mathrm{Al}-\mathrm{Li}$ alloys and ternary $\mathrm{Al}-\mathrm{Li}-\mathrm{Cu}$ alloys at the early stages of the decomposition of the microstructure.

The objective of this study in the context introduced above is to investigate the nano-scale chemical composition in the $\mathrm{Al}-\mathrm{Cu}, \mathrm{Al}-\mathrm{Li}$ and $\mathrm{Al}-\mathrm{Li}-\mathrm{Cu}$ alloys during the early stage of precipitation sequence and to describe whether this compositional difference correlates with variations in the observed precipitation kinetics. Knowledge of the decomposition process itself is particularly important for future technical developments.

\section{Material and Methods}

Three different alloys with different chemical compositions were prepared and heat-treated. The first alloy was an Al-1.7 at.\% $\mathrm{Cu}$ alloy. The ingot of this alloy was prepared from high purity materials. $\mathrm{Al}$ and $\mathrm{Cu}$ shots were arc-melted under an $\mathrm{Ar}$ atmosphere. Melting was repeated using inert-gas induction melting in a carbon crucible to ensure good mixing of the elements. The second alloy was an Al-8.2 at.\% Li alloy, which was bought as a master alloy due to the difficulty of its lab preparation; this difficulty was caused by the high diffusion coefficient of $\mathrm{Li}$ in the melt, which causes $\mathrm{Li}$ to typically fluidize on the top of the melt. The third alloy was an Al-4 at.\% Li-1.7 at.\% Cu alloy that was prepared by alloying $\mathrm{Cu}$ with an $\mathrm{Al}-4$ at.\% Li master alloy using induction melting. The inductive melting procedure melted the mixed $\mathrm{Al}, \mathrm{Cu}$ and $\mathrm{Li}$ at the casting temperature $\left(750^{\circ} \mathrm{C}\right)$ for $2 \mathrm{~min}$. All three alloys were cast into plates with dimensions of $30 \times 30 \times 30 \mathrm{~mm}^{3}$. After casting the samples, they were homogenized for 60 to $70 \mathrm{~min}$ at $513^{\circ} \mathrm{C}$ in a salt melt $\left(75 \mathrm{wt} . \% \mathrm{KNO}_{3}, 20\right.$ wt.\% $\mathrm{NaNO}_{3}, 5$ wt.\% $\left.\mathrm{NaNO}_{2}\right)$. The samples were cut using a low-speed diamond saw into a rod that was 30 um thick and $30 \mathrm{um}$ long. After cutting the samples, they were re-homogenized at $530^{\circ} \mathrm{C}$ for 20 min in high-vacuum quartzite ampules and then quenched in cold water. After water quenching from the homogenization temperature, each alloy was then artificially aged under three different conditions. A summary of the ageing conditions that were used in this study is shown in Table 1 along with their indication names. The abbreviations of the names of the artificial ageing conditions are used in the remainder of this paper. A chart that summarizes the preparation procedure is shown in Figure 1.

To prepare APT specimens, the raw material was first ground to a $200 \mu \mathrm{m}$ thickness and was then cut into blocks of $15 \times 0.2 \times 0.2 \mathrm{~mm}^{3}$ using a wire-saw machine. 


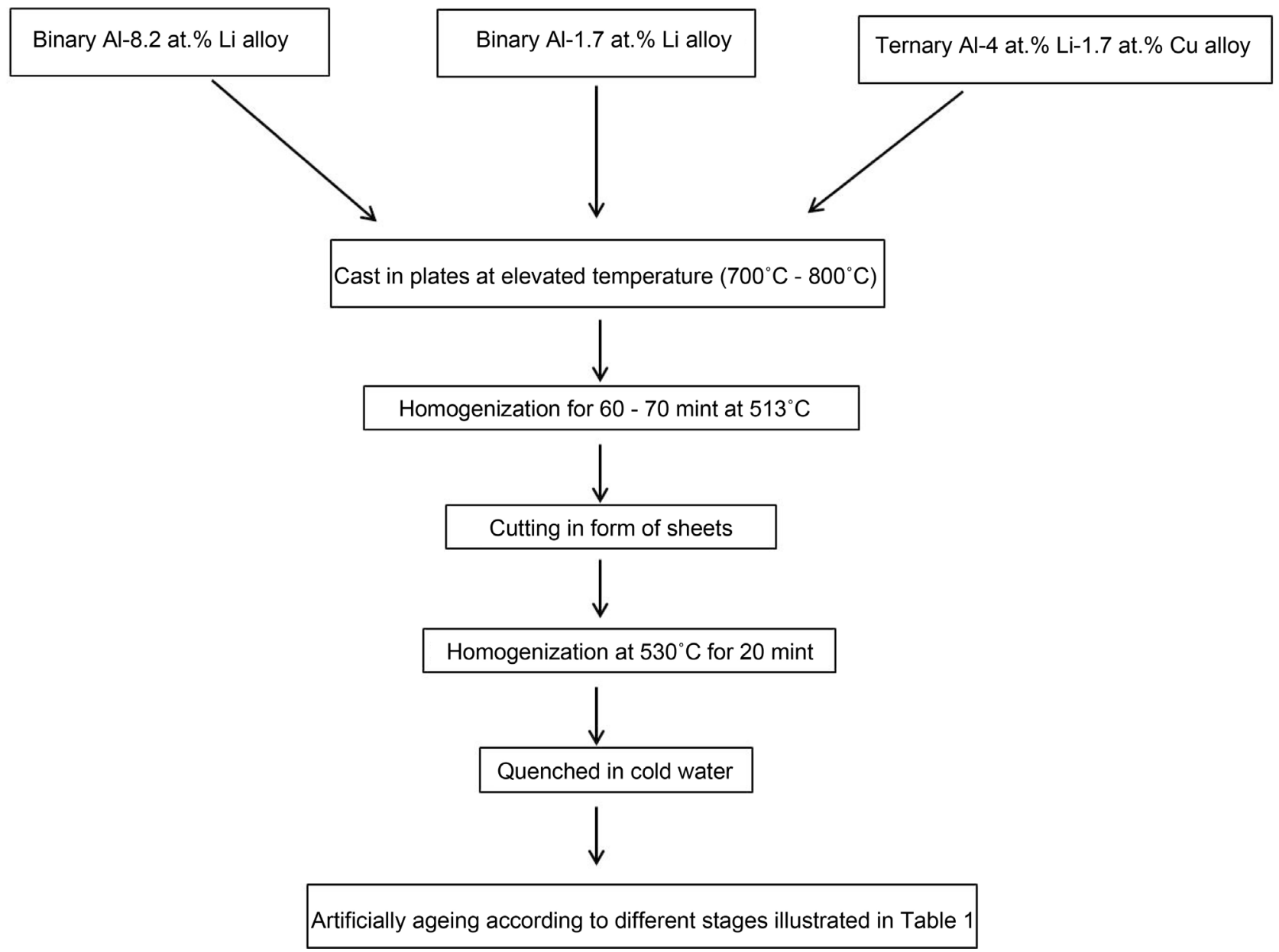

Figure 1. Summary of the preparation procedure of binary Al-Cu, Al-Li alloys and ternary Al-Cu-Li alloy.

Needle-shaped specimens were then fabricated using electro-polishing. This electropolishing procedure was performed in a solution containing $25 \mathrm{vol} . \%$ of nitric acid in methanol with a 3 - $5 \mathrm{~V}$ DC electric potential. APT analyses were performed in a Cameca LEAP HR 4000 (Local Electrode Atom Probe 4000) in voltage-pulse mode with a pulse fraction of $18 \%$ for the $\mathrm{Al}-\mathrm{Li}$ and $\mathrm{Al}-\mathrm{Li}-\mathrm{Cu}$ alloys, and $15 \%$ for $\mathrm{Al}-\mathrm{Cu}$ alloy. The specimens were maintained at a cryogenic temperature near $22 \mathrm{~K}$ for the $\mathrm{Al}-\mathrm{Li}$ and $\mathrm{Al}-\mathrm{Li}-\mathrm{Cu}$ alloys, and near $30 \mathrm{~K}$ for the $\mathrm{Al}-\mathrm{Cu}$ alloy under ultrahigh vacuum conditions of about $\mathrm{Pa}$. A detection rate of 0.001 ions per pulse was maintained throughout the experiments. Visualization and reconstruction of the data done by using IVAS, a software provided by Cameca. Different algorithms have been applied during the data treatment. These algorithms are: isoconcentration surface [25], cluster search [26] and the binomial distribution frequency statistics [27].

\section{Results and Discussion}

\subsection{Al-Cu Alloy}

Because APT is capable of resolving nano-scale microstructures including atomic clus- 
ters and other fine scale segregation effects, we used APT to analyze the microstructure of the three Al-1.7 at.\% $\mathrm{Cu}$ alloys, which have been subjected to the three heat treatment conditions shown in Table 1 (i.e., $1 \mathrm{~S}, 2 \mathrm{~S}$ and $3 \mathrm{~S}$ ). An atomic probe mass spectrum of $\mathrm{Al}-1.7$ at.\% $\mathrm{Cu}$ alloys that have been aged based on $1 \mathrm{~S}$ or $2 \mathrm{~S}$ or $3 \mathrm{~S}$ shows the presence of some $\mathrm{Al}$ ions which were detected as hydrides (i.e. $\mathrm{AlH}_{2}^{+}$), and some $\mathrm{Cu}$ ions which were also detected as hydrides (i.e. $\mathrm{CuH}_{2}^{+}$). The formation of these hydrides is most likely caused by the residual gas inside the analysis chamber. However, whatever the origin of the hydrogen, it apparently does not affect the analysis because the overall average composition obtained by APT analysis is close to the nominal alloy composition.

Figure 2(a) shows a typical view of $\mathrm{Cu}$-atom distributions from different APT experiments on $\mathrm{Al}-1.7$ at.\% $\mathrm{Cu}$ alloys that have already been subjected to $1 \mathrm{~S}$ or $2 \mathrm{~S}$ or $3 \mathrm{~S}$ heat treatments. The figure shows that there is no spatial correlation in the distributions of the $\mathrm{Cu}$ atoms. Binomial frequency distribution analysis has been used to identify the presence of nano-scale solute-clustering processes and other segregations, which are sometimes difficult to visualize in APT datasets. Using this methodology, the identification of fine-scale solute clustering in the early stage of phase decomposition in the alloy investigated in this study is possible. A detailed explanation of the quantitative binomial distribution analysis of nano-scale atom clustering and segregation in the APT data can be found in reference [28]. The binomial distribution of the $\mathrm{Cu}$ atoms in Figure 2(a) is plotted together with the experimental frequency distribution in Figure 2(b), which shows a good agreement between the binomial distribution and the experimental frequency distribution. This suggests homogeneity of the microstructures and thus indicates that $\mathrm{Cu}$ has not clustered under these heat treatment conditions. An additional nearest neighbor analysis did also not give any reason to expect the existence of

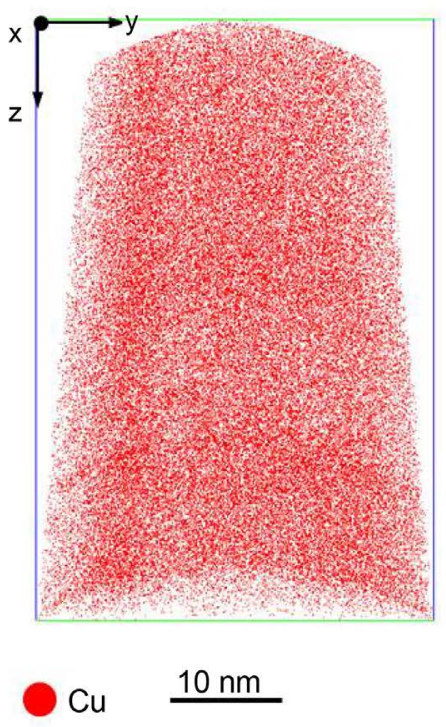

(a)

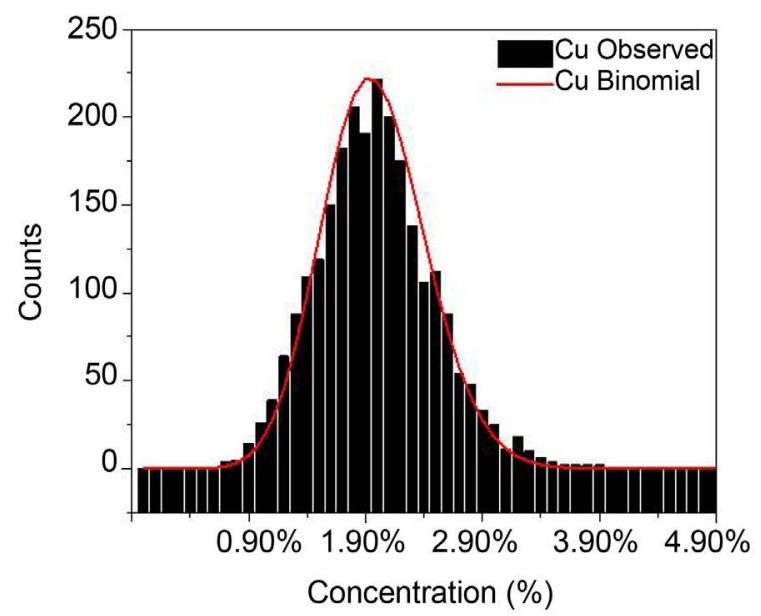

(b)

Figure 2. $\mathrm{Cu}$ distribution within $\mathrm{Al}-1.7$ at.\% $\mathrm{Cu}$ dataset corresponding to the three stages of heat treatments: (a) The reconstructed volume. (b) Binomial and experimental frequency distribution. 
clusters. To determine when precipitation starts, the ageing time was increased to 30 min, and the ageing temperature to $200^{\circ} \mathrm{C}$. Figure 3 (a) shows the APT datasets that were experimentally acquired to evaluate the microstructure for the specimens that were heat-treated by increasing both the ageing time and the ageing temperature. The $3 \mathrm{D}$ reconstruction shows the position of $\mathrm{Cu}$ atoms. Again, the binomial frequency distribution analysis is used to study the evaluation of the clustering of $\mathrm{Cu}$ atoms (Figure $3(b))$. The agreement between the binomial distribution and the experimental frequency distribution and analysis of the nearest neighbors suggests homogeneity of the microstructure in this case, too.

The second step in the context of the evaluation of the precipitation sequence in $\mathrm{Al}-\mathrm{Cu}$ system is to increase the ageing time to $8 \mathrm{~h}$ while maintaining the temperature at $160^{\circ} \mathrm{C}$. Applying this ageing condition produced a thin platelet of $\theta$, as shown in the $3 \mathrm{D}$ reconstruction in Figure 4(a), where only $\mathrm{Cu}$ atoms are shown. A comparison between the binomial distribution and experimental distribution in Figure 4(b) shows a clear shift between the two curves, which is an indication that the $\mathrm{Cu}$ atoms are arranging as second-phase particles. The chemical composition of the $\theta^{\prime}$ phase in this case is determined to be $(15.2 \pm 4)$ at.\% $\mathrm{Cu}$. This is based on the composition profile forms from the isoconcentration surface of 8 at.\% Cu (Figure 4(c)).

The absence of clusters of $\mathrm{Cu}$ atoms, GP zones and $\theta^{\prime}$ precipitates from the microstructure of the specimens subjected to the three heat-treatment conditions in Table 1 (1 S, $2 \mathrm{~S}$ and $3 \mathrm{~S}$ ) (Figure 2) and from the microstructure of the specimens heat treated with increasing ageing time and ageing temperature (Figure 3) can be explained as follows: The lack of nano-features in this case is based on the vacancy concentrations. It seems that under these heat-treatment conditions, the $\mathrm{Cu}$ atoms are not able to cluster

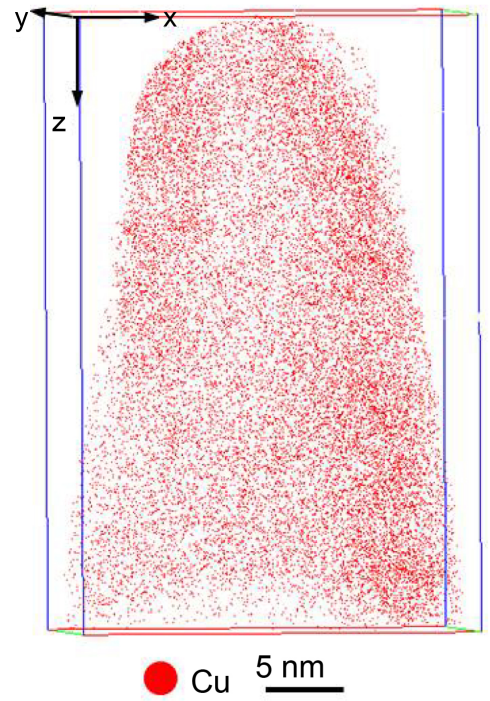

(a)

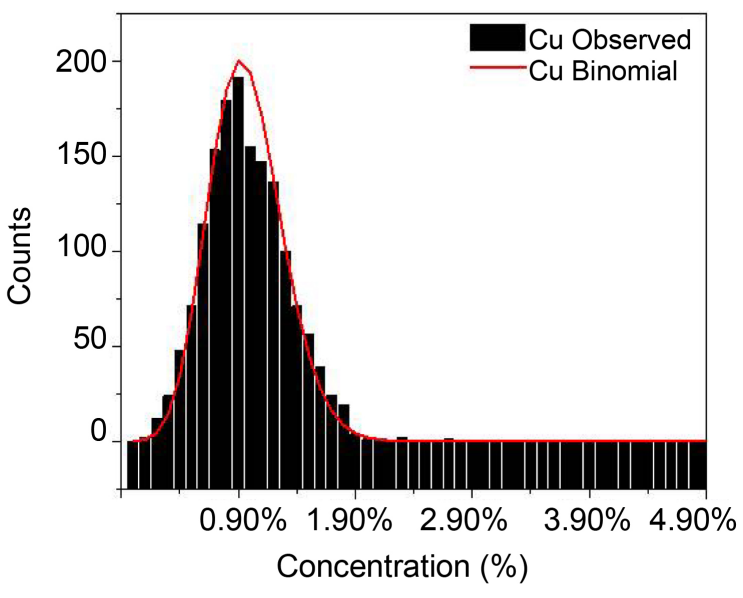

(b)

Figure 3. $\mathrm{Cu}$ distribution within $\mathrm{Al}-1.7$ at.\% $\mathrm{Cu}$ dataset corresponding to heat treated with increasing aging time to $30 \mathrm{~min}$ at $200^{\circ} \mathrm{C}$. (a) The reconstructed volume. (b) Binomial and experimental frequency distribution. 


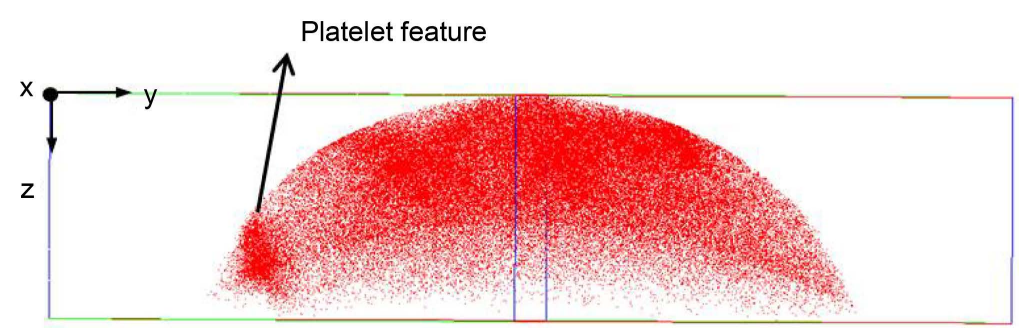

Cu $\quad \underline{5 \mathrm{~nm}}$

(a)

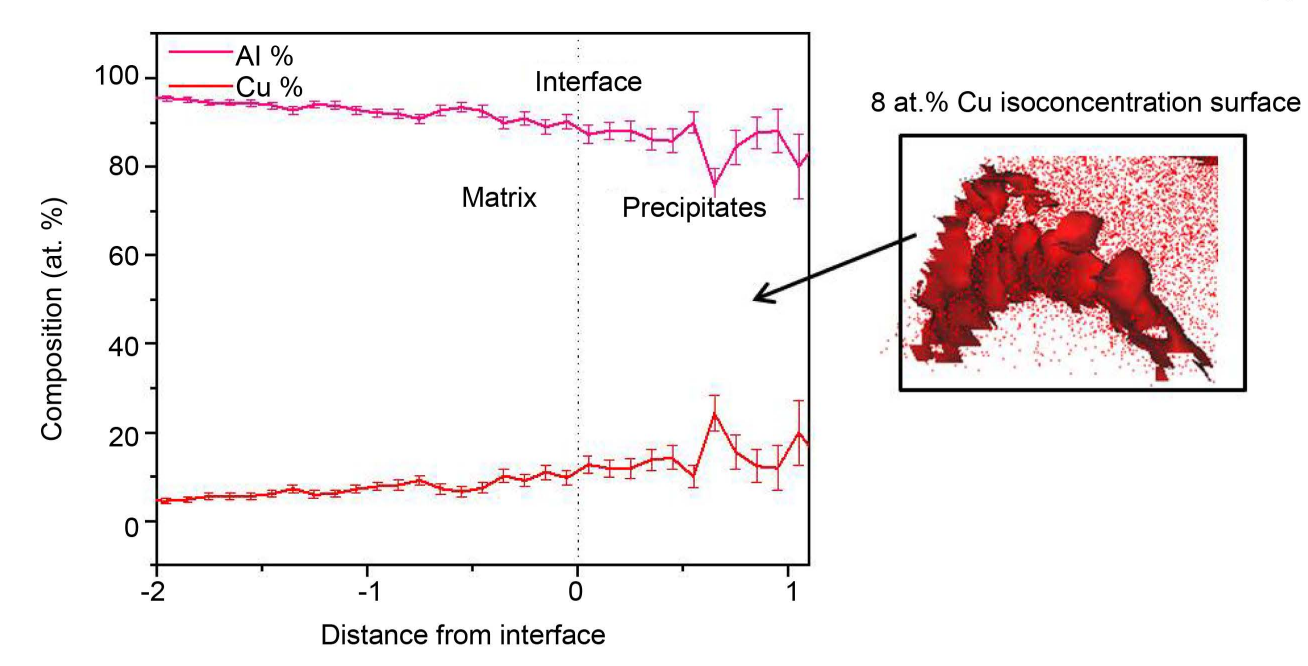

(c)

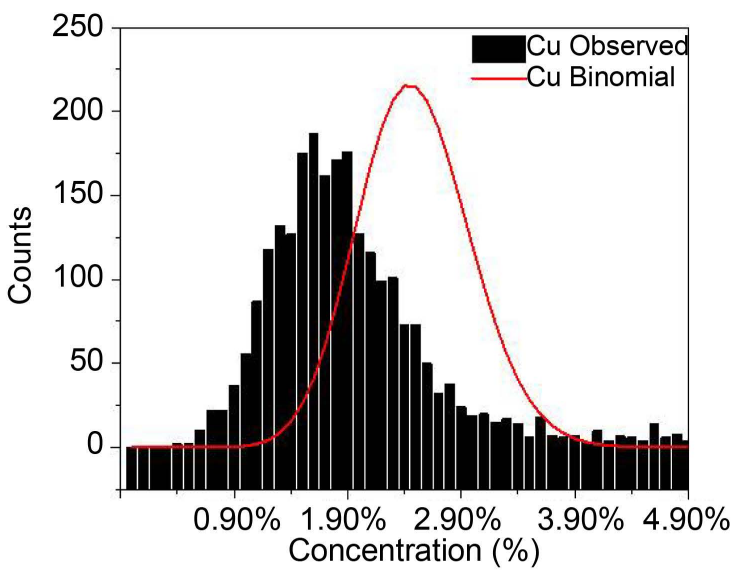

(b)

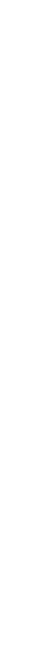

Figure 4. $\mathrm{Cu}$ distribution within $\mathrm{Al}-1.7$ at. \% $\mathrm{Cu}$ dataset corresponding to aging the alloy for $8 \mathrm{~h}$ at $160^{\circ} \mathrm{C}$. (a) The reconstructed volume showing the presence of platelet feature. (b) Binomial and experimental frequency distribution. (c) Composition profile of the platelet from isoconcentartion surface of 8 at.\% $\mathrm{Cu}$.

together and thus nucleate and grow; this phenomenon might be due to a diminished excess-vacancy concentration, which arises from vacancy sink sources. Increasing the ageing temperature to $200^{\circ} \mathrm{C}$ causes a reduction of the driving force for particle nucleation [29]. Additionally, kinetic limitations during the precipitation sequence in this system are perhaps due to the low diffusivity of $\mathrm{Cu}$ into $\mathrm{Al}$ (diffusion coefficient $D=$ $0.89 \times 10^{-20} \mathrm{~m}^{2} \mathrm{~s}^{-1}$ at $190^{\circ} \mathrm{C}$ ) [30].

The ageing treatment at $160^{\circ} \mathrm{C}$ for $8 \mathrm{~h}$ produces thin platelet precipitates that were identified as $\theta^{\prime}$ platelets. The low density of the $\theta^{\prime}$ platelets under this ageing condition might be related to the short ageing time $(8 \mathrm{~h}) .20$ vol.\% $\theta^{\prime}$ precipitates were reported for ageing an Al-4 wt.\% $\mathrm{Cu}$ alloy for 3.5 days [31]. The transformation of GP zones into $\theta$ 'precipitates occurred when the ageing time was $>48 \mathrm{~h}$ [32]. The difficulty of detecting GP zones in the microstructure of the proposed alloy system is owing to the limited resolution of the obtained APT data. The off-stoichiometry of the $\theta$ 'platelet in Figure 4 
stills an open issue. It might be explained due to a limited $\mathrm{Cu}$ diffusion and a limited formation of point defects.

Based on the Al-Cu phase diagram [33], the full sequence of the transition precipitate will be observed only if annealing or ageing is performed below the GP zone precipitate solvus (i.e., nearly $100^{\circ} \mathrm{C}$ ) with a long ageing time due to the low diffusivity of $\mathrm{Cu}$ into Al. The large diameter and small density of the different precipitates represent other challenges to analyze in the complex precipitation sequence in $\mathrm{Al}-\mathrm{Cu}$ systems.

\subsection{Al-Li Alloy}

APT has been used to analyze Al-8.2 Li at.\% alloys that have been subjected to the three stages of heat treatment (i.e., $1 \mathrm{~S}, 2 \mathrm{~S}$ and $3 \mathrm{~S}$ ) shown in Table 1. Example of the APT datasets which were experimentally acquired for the specimens under the $1 \mathrm{~S}$ or $2 \mathrm{~S}$ ageing conditions to examine the evolution of the microstructure at the early stage of decomposition is shown in Figure 5(a). Comparing the binomial distribution and the experimental distribution in Figure 5(b) shows a marginal shift between the two curves.

It seems that individual applying of the natural annealing condition and individual applying of the artificial ageing condition at $160^{\circ} \mathrm{C}$ for $5 \mathrm{~min}$ alone does induce the formation of small clusters of $\mathrm{Li}$ atoms. These are observed in the microstructure after applying the cluster-search algorithm on the dataset with and order number of 3 for $\mathrm{Li}$ atom. A statistical calculation based on findings from applying cluster search algorithms show that the microstructure under $1 \mathrm{~S}$ and $2 \mathrm{~S}$ heat treatment conditions contains Li clusters with size of $(1.3 \pm 0.3) \mathrm{nm}$, chemical composition of $(20 \pm 1.5)$ at.\% Li and number density ranges between $3-4 \times 10^{23} \mathrm{~m}^{-3}$ (Figure $5(\mathrm{c})$ ). It worth to mention, that the selection of cluster search parameters was performed based on nearest neighbor investigations [27] that examine the interatomic separation in the immediate vicinity around each $\mathrm{Li}$ atom. The distribution distances separating each $\mathrm{Li}$ atom and the nearest other $\mathrm{Li}$ atoms in $\mathrm{Al}-8.2$ at.\% $\mathrm{Li}$ dataset compare to the distances that would be expected if the atoms in solution were random is shown in Figure 6.

However, the shift between the binomial and experimental distributions becomes more pronounced when the specimen is heat-treated under the $3 \mathrm{~S}$ ageing condition (i.e., a combination of natural and artificial ageing), as shown in Figure 7. The experimental distribution calculated from the reconstructed volume in Figure 7(a) is shown to be shifted to the left compared to its corresponding binomial distribution (Figure $7(b))$. Thus, the presence of second-phase particles can expect in this microstructure. Applying the cluster-search algorithm on the dataset in Figure 7(a) (with the same cluster search parameters as in Figure 5) shows the presence of $\mathrm{Li}$ atoms clusters with size of $(2.1 \pm 0.2) \mathrm{nm}$ and chemical composition of $(22.2 \pm 1)$ at.\% Li (Figure $7(\mathrm{c})$ ). The number density of Li clusters under this aging condition is recorded as $6 \times 10^{23} \mathrm{~m}^{-3}$. It is worth notable that the number density of Li clusters in the microstructure under $3 \mathrm{~S}$ heat treated condition is higher than that in the microstructure under $1 \mathrm{~S}$ or $2 \mathrm{~S}$ heat treated conditions by around two orders of magnitude. 


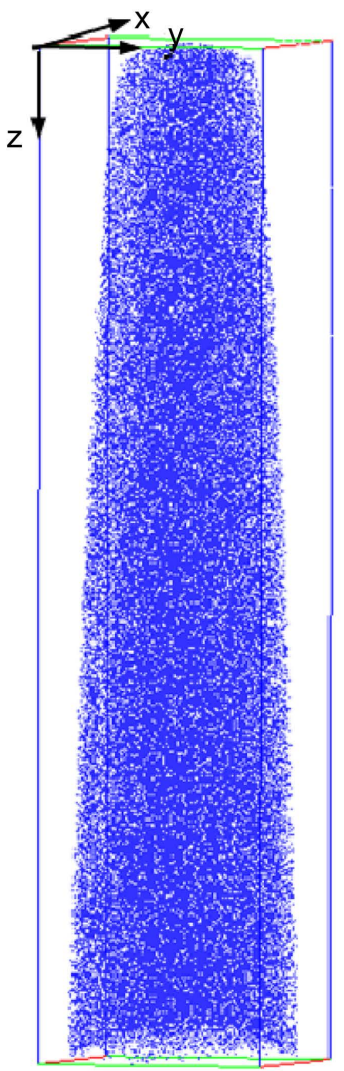

$10 \mathrm{~nm}$

$\mathrm{Li}$

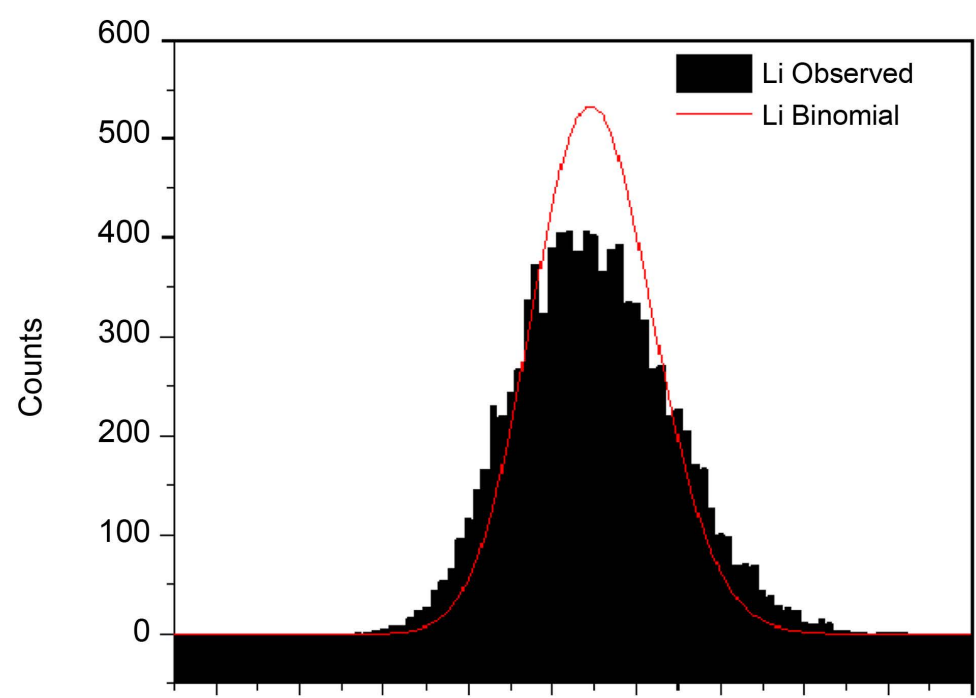

0.90\% 1.90\% 2.90\% 3.90\% 4.90\% 5.90\% 6.90\% 7.90\% 8.90\% 9.90\%

\section{Concentration (\%)}

(b)

(a)
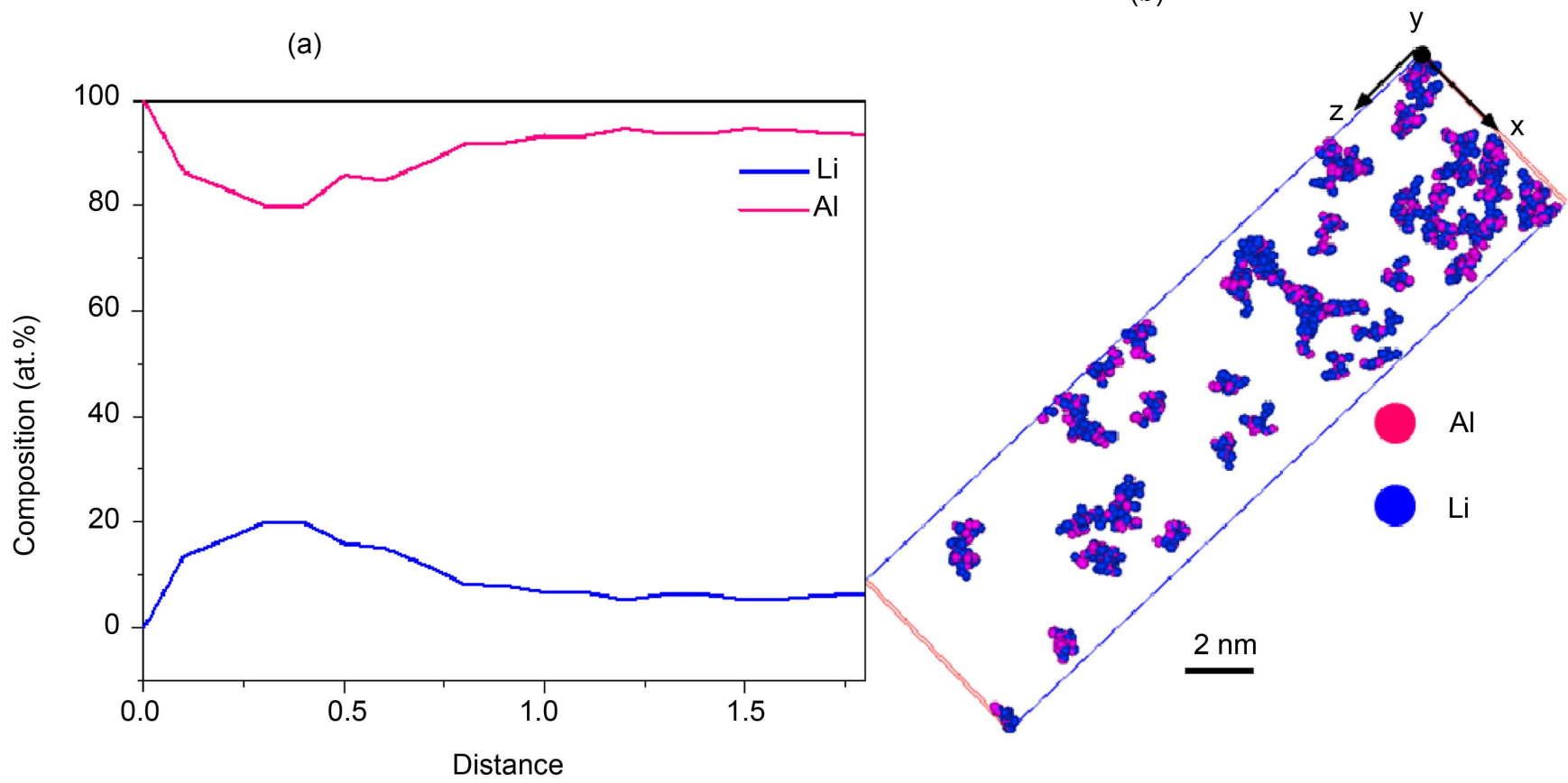

(c)

Figure 5. Li distribution within Al-8.2 at.\% Li dataset corresponding to the two stages of heat treatments: (a) The reconstructed volume. (b) Binomial and experimental frequency distribution. (c) Distribution of Al-Li clusters with the chemical composition. 


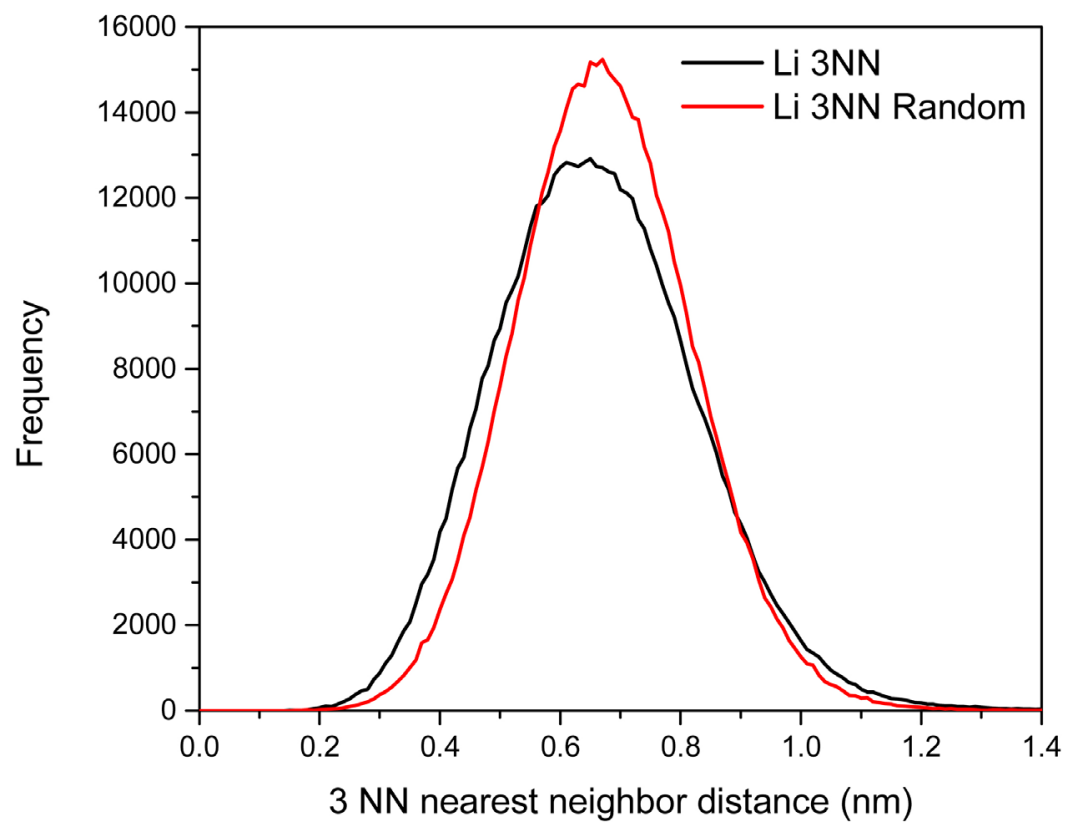

Figure 6. Distribution of distance separating in Al-8.2 at.\% Li for each $\mathrm{Li}$ atom and its third neighbor.

The presence of second-phase particles or clusters of $\mathrm{Li}$ atoms from the microstructure of the samples heat treated with $1 \mathrm{~S}$ and $2 \mathrm{~S}$ conditions (Figure 5) is expected because a number of studies reported the presence of $\delta^{\prime}$ particles in quenched samples [9] [13]. For our case, observation of these particles has been recorded statistically based on applying the cluster-search algorithm to the datasets (Figure 5(c)). A possible explanation for the observation in Figure 5 can be a high concentration of vacancies in the microstructure. It has been reported that in Al-Li systems, quenched vacancies and thermal vacancies play important roles in the kinetics [34]. An import factor in controlling the kinetics when ageing after quenching is solute-vacancy binding, where the suggested path is that vacancies become coupled to $\mathrm{Li}$ atoms during quenching. Ceresaraa et al. [34] claims that vacancy-Li couples can be reduced during quenching at the recovery stage in case of Al-0.38 at.\% Li alloy. However, this recovery procedure is unexpected in our respective alloy with high supersaturation of $\mathrm{Li}$ (8.2 at.\%). The presence of a sufficient density of $\delta^{\prime}$ particles (or Li clusters) in the microstructure of our naturally aged sample can be explained by the coupling of $\mathrm{Li}$ atoms with quenched vacancies, while thermal vacancies play an important role when the specimen is aged at $160^{\circ} \mathrm{C}$ for $5 \mathrm{~min}$, i.e. under $2 \mathrm{~S}$ condition. The microstructure of specimen under the combination of natural and artificial ageing conditions contains a higher number density of Li clusters. This could be explained by the higher density of quenched vacancies that start clustering during the natural aging. The thermal vacancies during the artificial aging contribute then to the formation of the $\delta^{\prime}$ particles, as shown in Figure 7 (c).

\subsection{Al-Li-Cu Alloy}

To understand the early stage of decomposition of the microstructure of ternary Al-4 


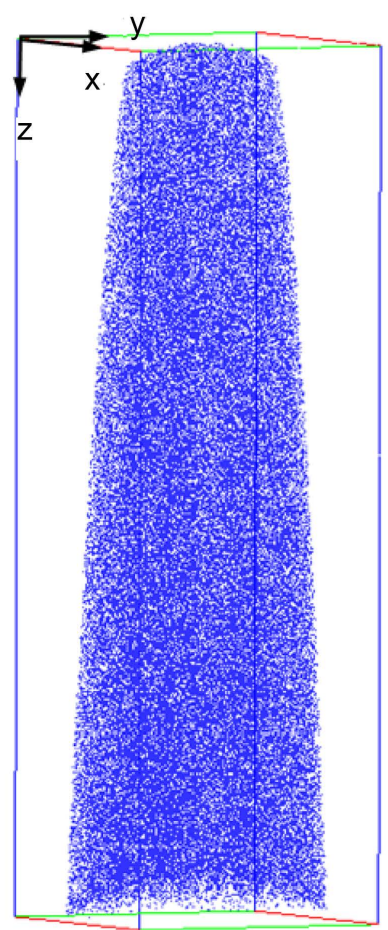

Li $\quad 10 \mathrm{~nm}$

(a)

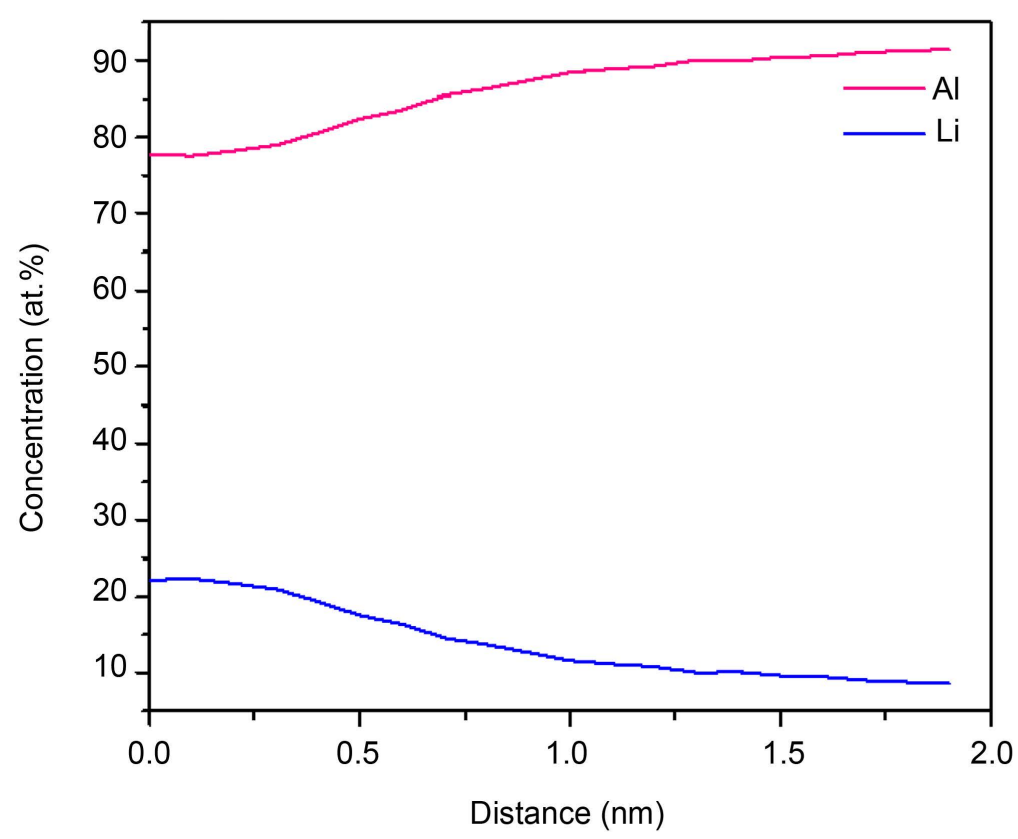

(c)

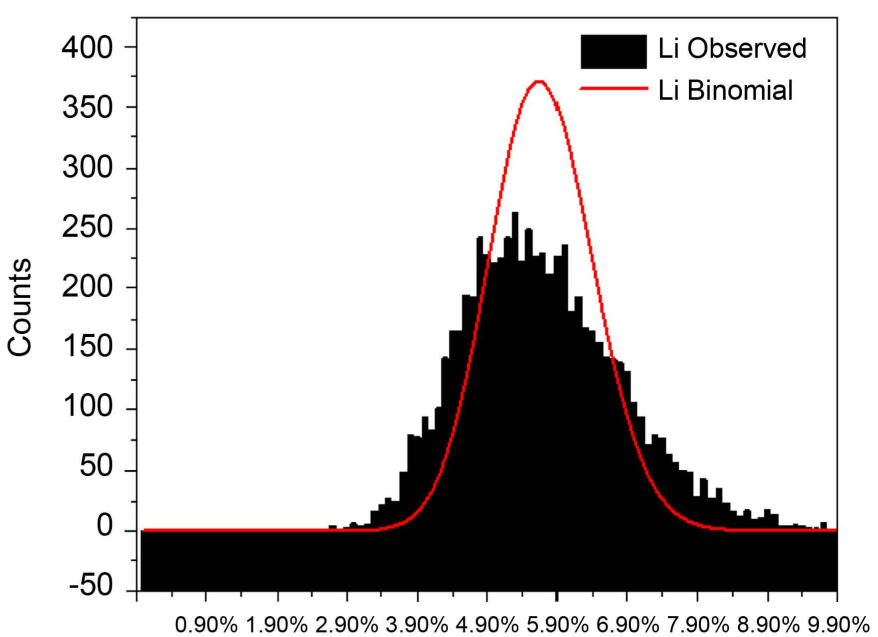

Concentration (\%)

(b)

10 at. \% Li isoconcentration surface

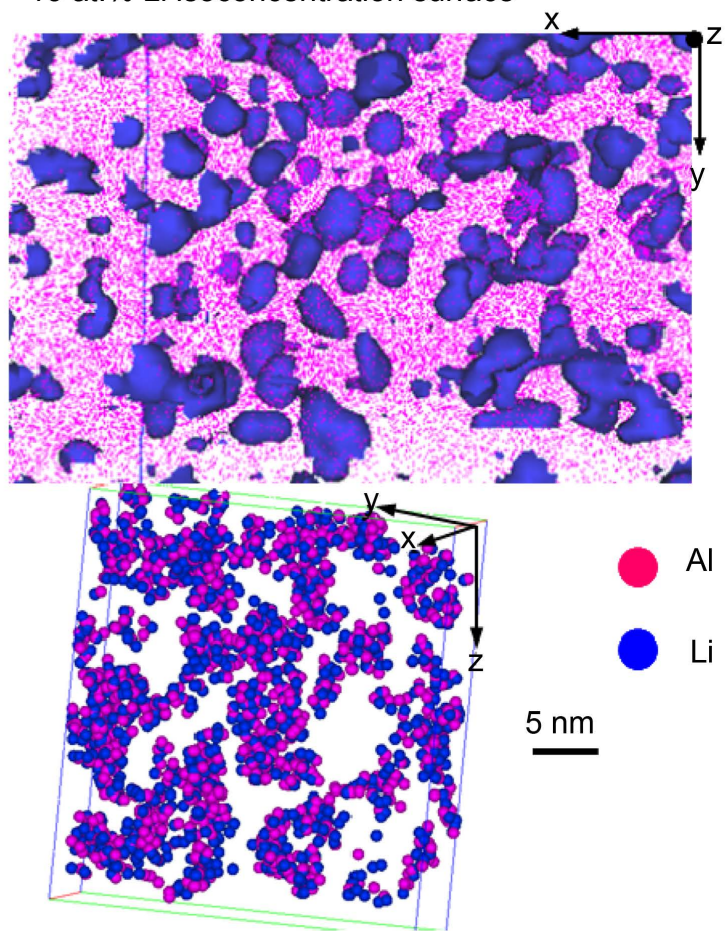

Figure 7. Li distribution within Al-8.2 at.\% Li dataset corresponding to the $3 \mathrm{~S}$ condition (a) The reconstructed volume. (b) Binomial and experimental frequency distribution. (c) Distribution of Al-Li clusters with the chemical composition profile and the inset corresponds to isoconcentration surface of 10 at.\% Li. 
at.\% Li-1.7 at.\% $\mathrm{Cu}$ alloy, APT experiments were performed for the specimens that were heat-treated based on the three stages (1 S, $2 \mathrm{~S}$ and $3 \mathrm{~S}$ ) shown in Table 1. In figure 8, a typical $\mathrm{Cu}$ and $\mathrm{Li}$ atom maps are provided, which are from APT experiments on the ternary alloy that were subjected to $1 \mathrm{~S}$ and $2 \mathrm{~S}$ ageing conditions. Similar to the situation in Figure 2 and Figure 5 for Al-Cu and Al-Li alloys, which have experienced the $1 \mathrm{~S}$ and $2 \mathrm{~S}$ ageing conditions, the absence of inhomogeneity in the microstructure is shown in Figure 8(a); this is also confirmed by comparing the binomial distribution to the experimental frequency distribution in Figure $8(\mathrm{~b})$. No shifting between the two curves of the $\mathrm{Li}$ and $\mathrm{Cu}$ atoms is found, which supports assuming the absence of any clustering or solute-atom segregation under these conditions. Nearest Neighbor analyses for $\mathrm{Li}$ and $\mathrm{Cu}$ also do not show any signs of clustering. The possible explanation of this observation is the low vacancy concentrations which might delay the clustering event.

Conversely, the reconstructed volume of the specimen that was heat-treated under the $3 \mathrm{~S}$ ageing condition in Figure 9(a) shows an inhomogeneous distribution, particularly for $\mathrm{Cu}$ atoms. The experimental distribution calculated from this reconstructed volume is shown in Figure 9(b). The experimental distribution for the $\mathrm{Cu}$ atoms is shifted to the left, while the difference is smaller for the Li atoms. Applying the isoconcentration procedure in the reconstructed volume in Figure 9(a) visualizes enriched

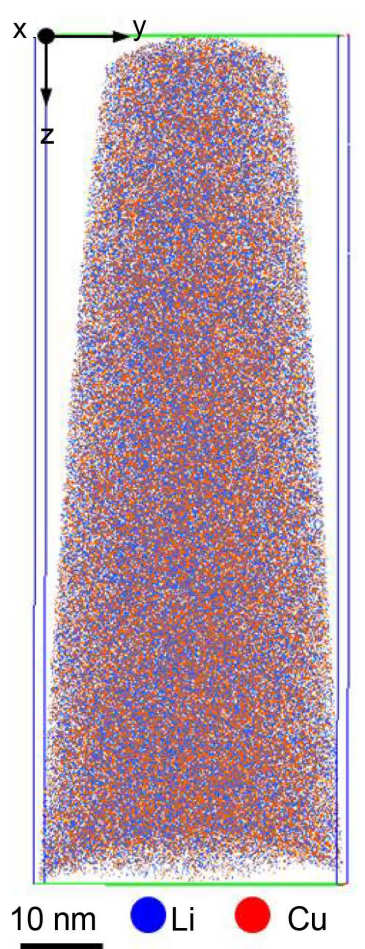

(a)

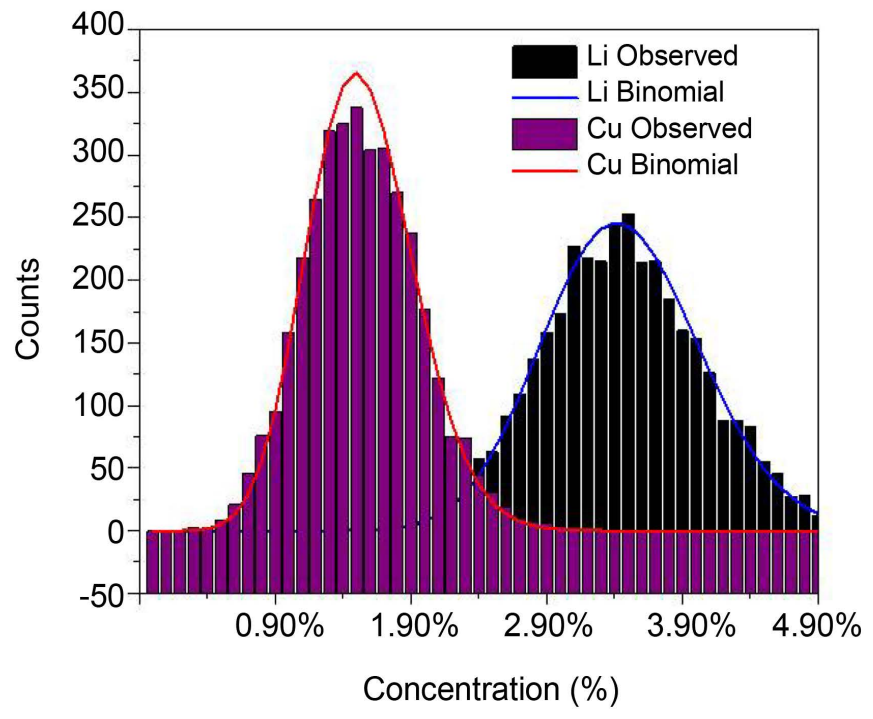

(b)

Figure 8. $\mathrm{Cu}$ and $\mathrm{Li}$ distribution within $\mathrm{Al}-4$ at.\% $\mathrm{Li}-1.7$ at.\% $\mathrm{Cu}$ dataset corresponding to the two stages of heat treatments 1 S, 2 S. (a) The reconstructed volume. (b) Binomial and experimental frequency distribution for both $\mathrm{Cu}$ and $\mathrm{Li}$ atoms. 


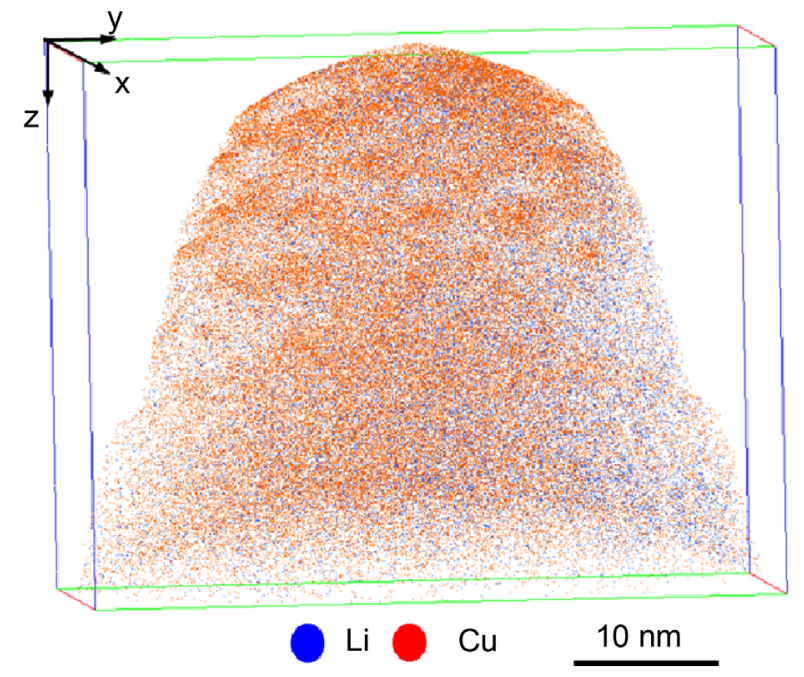

(a)

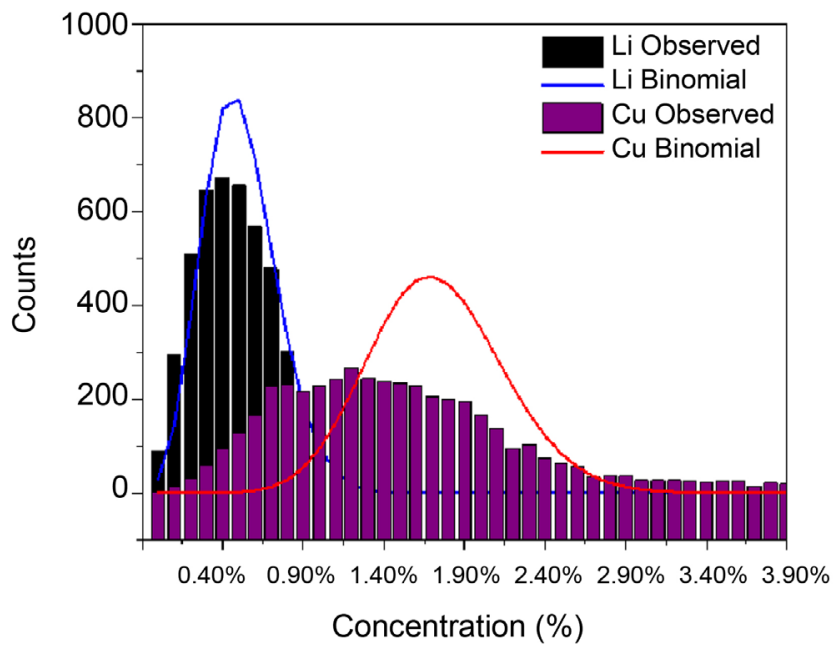

(b)

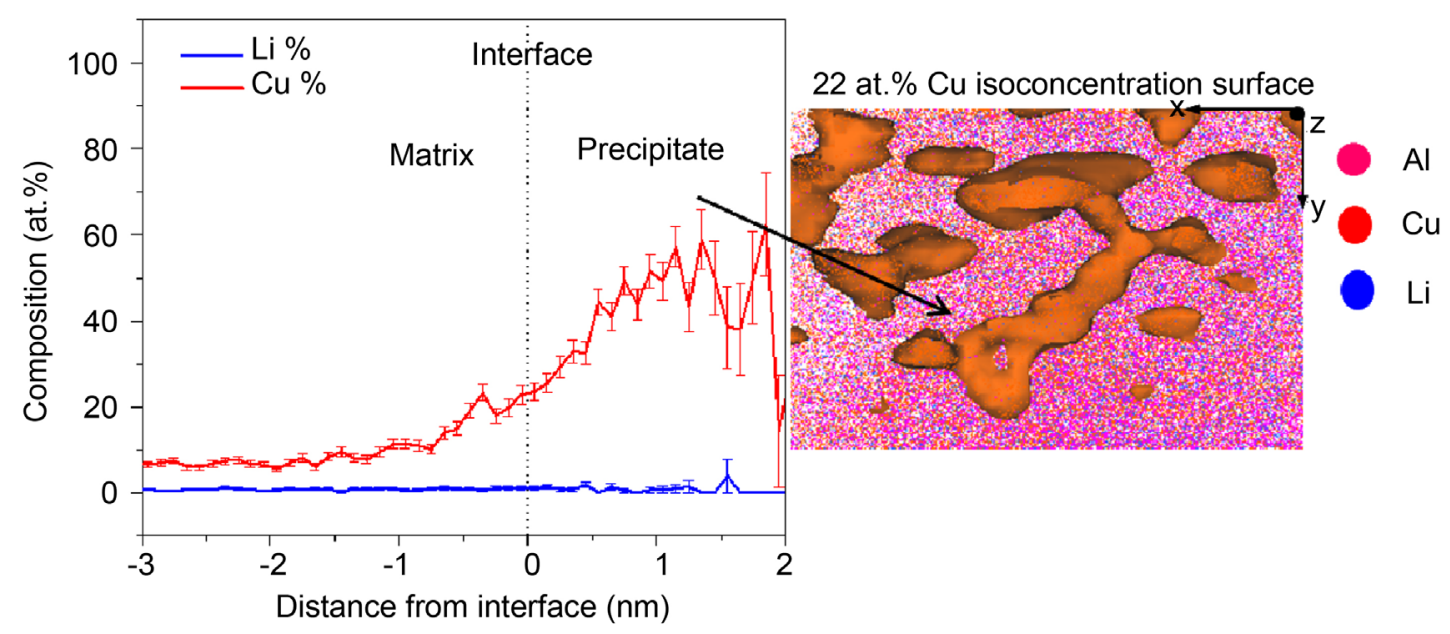

(c)

Figure 9. $\mathrm{Cu}$ and $\mathrm{Li}$ distribution within $\mathrm{Al}-4$ at.\% Li-1.7 at.\% $\mathrm{Cu}$ dataset corresponding to the $3 \mathrm{~S}$ aging condition. (a) The reconstructed volume showing inhomogeneity in $\mathrm{Cu}$ distribution. (b) Binomial and experimental frequency distribution for both $\mathrm{Cu}$ and $\mathrm{Li}$ atoms. (c) Composition profile through the 22 at.\% Cu isoconcentration surface of the enriched Cu region visualizes the precipitation of the platelet.

region of $\mathrm{Cu}$ atoms that is decorated sparsely with $\mathrm{Li}$ atoms. The chemical composition of this enriched region is shown in Figure 9(c). Based on the quantitative analysis in Figure 9(c), the chemical composition of the $\mathrm{Cu}$-enriched region (from the isoconcentration surface of 22 at. $\% \mathrm{Cu})$ is $(33 \pm 1)$ at.\% $\mathrm{Cu},(5.3 \pm 1)$ at.\% Li. Thus, the $\mathrm{Cu}$-enriched region can be identified as a $\theta^{\prime}$ precipitate.

The equilibrium phases in Al-Li-Cu phase diagram [15] for the compositions of interest are $T_{1}, T_{2}$ and $T_{3}$. However, none of these phases have been detected in the APT analyses performed (Figure 8 and Figure 9); this result could be explained by the similarity of the precipitation processes in both $\mathrm{Cu}$-rich alloys and binary $\mathrm{Al}-\mathrm{Cu}$ alloys [35]. The presence of Li atoms might modify the orientation relation and structure of the homogenously nucleated zone [10]. The Li atoms are also known to enhance the preci- 
pitation of the $\theta^{\prime}$ phase, as shown in Figure 9(c). Based on this analysis, it can be concluded that the early stage of the ternary $\mathrm{Al}-4$ at.\% Li-1.7 at.\% $\mathrm{Cu}$ alloy starts by the precipitation of the $\theta^{\prime}$ phase which is enriched with $\mathrm{Li}$, and thus would be transfer to the phase at the later stage of ageing.

To investigate the influence of changing the composition on the precipitation behavior, a new ternary alloy with a nominal composition of Al-8 at.\% Li-1.7 at.\% Cu was prepared based on the preparation procedure shown in Figure 1. Only the $3 \mathrm{~S}$ ageing condition was applied. Different from the situation in Figure 9(a), the microstructure of this specimen is rather homogenous (Figure 10(a)). No difference between the binomial and experimental frequency distributions for both $\mathrm{Cu}$ and $\mathrm{Li}$ atoms was detected (Figure 10(b)). A nearest neighbor analysis also showed no clustering. The

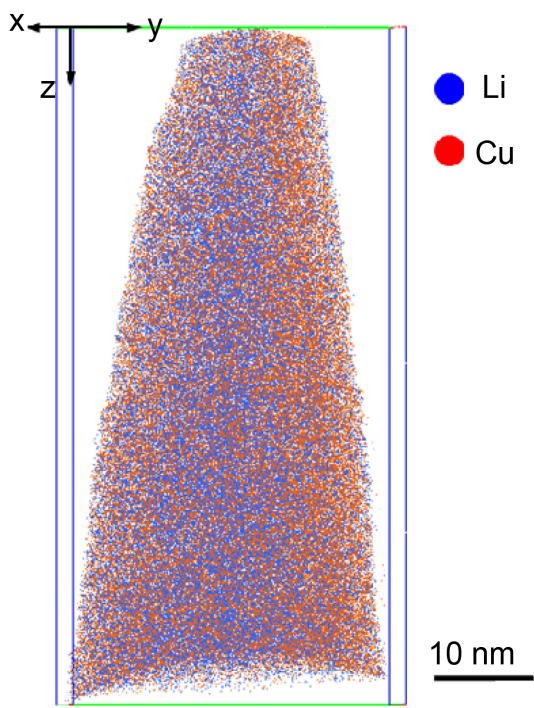

(a)

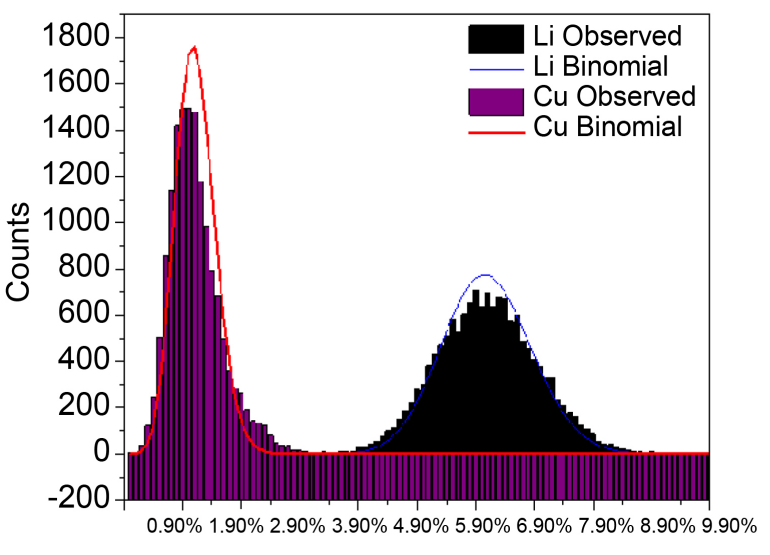

Concentration (\%)

(b)

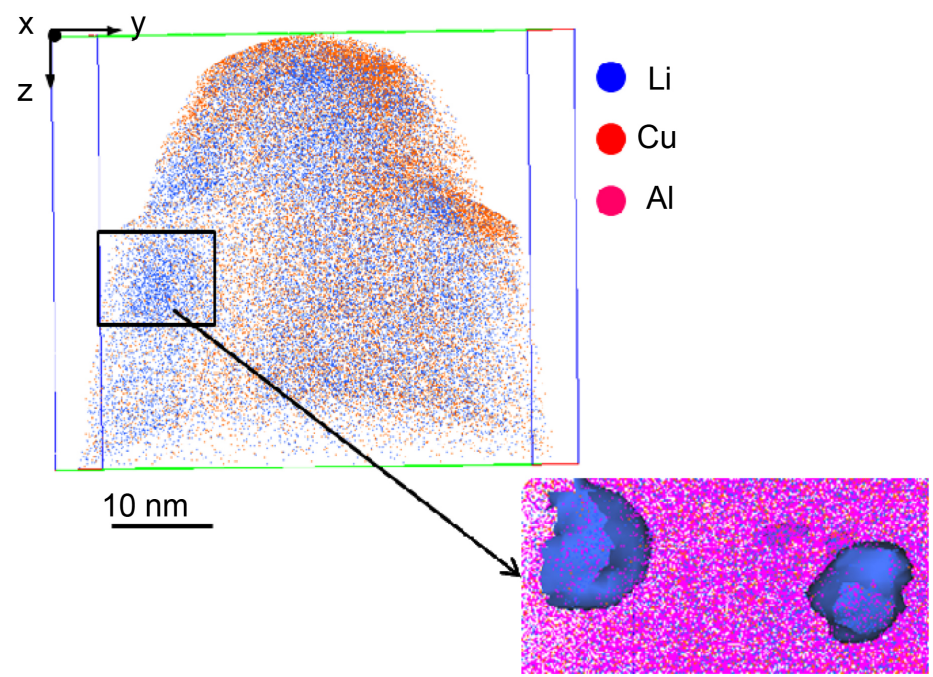

(c)

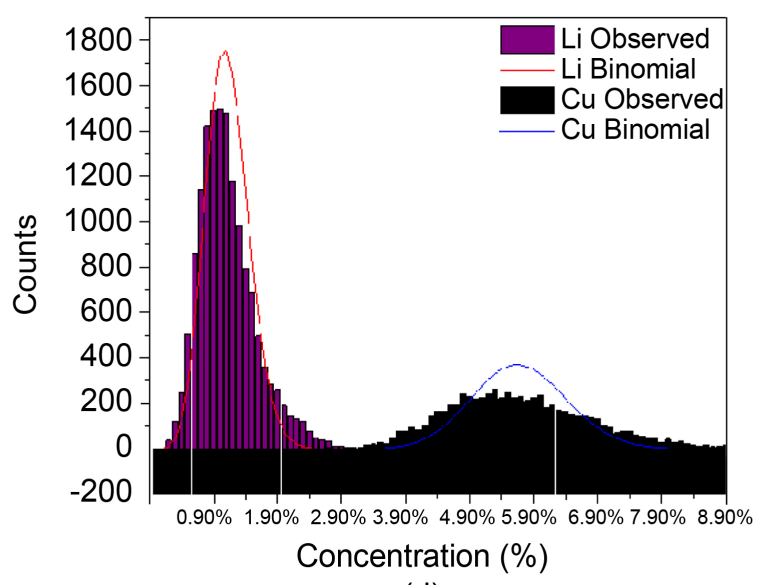

(d)

Figure 10. $\mathrm{Cu}$ and $\mathrm{Li}$ distribution within Al-8.2 at.\% Li-1.7 at.\% Cu dataset. (a) At the $3 \mathrm{~S}$ aging condition. (b) Binomial and experimental frequency distribution for both $\mathrm{Cu}$ and $\mathrm{Li}$ atoms in the reconstructed volume in (a) (c) The reconstructed volume of the specimen after aging the alloy for $30 \mathrm{~min}$ at $160^{\circ} \mathrm{C}$. (a) (d) Binomial and experimental frequency distribution for both $\mathrm{Cu}$ and Li atoms in the reconstructed volume in (c). 
homogeneity of the microstructure in Figure 10 is likely caused by Li atoms that, with their high vacancy binding energy $(0.26 \mathrm{eV})$, block excess vacancies and postpone or prevent the precipitation reaction of $\mathrm{Cu}$. However, increasing the ageing time to $30 \mathrm{~min}$ for this alloy drastically changes the outcome; in this case $\delta^{\prime}$ are clearly present in Figure 10(c). The deviation from the binomial distribution is shown in Figure 10(d), indicating that $\mathrm{Li}$ atoms are not fully homogenously distributed in the matrix. Thus one can conclude that a marginal change in the ageing time induces the precipitation of $\delta^{\prime}$ particles, and that the solubility of $\mathrm{Li}$ in $\mathrm{Al}$ does not seem to be affected by the presence of $\mathrm{Cu}$ atoms.

Finally, from this comparison of the three studied samples, it is clear that the $\theta^{\prime}$ phase is the dominant phase in the binary Al-1.7 at.\% Cu alloy, while the $\delta^{\prime}$ is the dominant one in the binary Al-8.2 at.\% Li alloy. On the other hand, in the ternary Al-4 at.\% Li-1.7 at.\% $\mathrm{Cu}$ alloy, the microstructure decomposition ends up with the formation of $\mathrm{Cu}$-rich phase (the $\theta^{\prime}$ phase), while increasing the Li content in this ternary alloy up to 8 at.\% induces the formation of $\delta^{\prime}$ particles.

\section{Conclusions}

In this study, an APT method with a comparing between binomial frequency distribution and experimental frequency distribution that quantifies the deviation from the random has been proposed to investigate the early stage of decomposition of the microstructure of a binary Al-1.7 at.\% Cu alloy, a binary Al-8.2 at.\% Li alloy and a ternary Al-4 at.\% Li-1.7 at.\% Cu alloy.

Atomic resolution microscopy experiments in conjunction with a statistical test demonstrate that the phase decomposition in $\mathrm{Al}-1.7$ at.\% $\mathrm{Cu}$ alloy requires a long ageing time of approximately $8 \mathrm{~h}$ at $160^{\circ} \mathrm{C}$ to allow the diffusion of $\mathrm{Cu}$ atoms into $\mathrm{Al}$ matrix. For the Al-8.2 at.\% Li alloy, a combination of both the natural ageing condition (48 $\mathrm{h}$ at room temperature) and a short artificial ageing condition $\left(5 \mathrm{~min}\right.$ at $160^{\circ} \mathrm{C}$ ) increases the size and the number density of the observed $\delta^{\prime}$ particles. Applying this combination of natural ageing and short artificial ageing conditions onto a ternary Al-4 at.\% $\mathrm{Li}-1.7$ at.\% $\mathrm{Cu}$ alloy induces the formation of a $\mathrm{Cu}$-rich phase (i.e., the $\theta^{\prime}$ phase). Increasing the Li content in the ternary alloy up to 8 at.\% and increasing the ageing time to $30 \mathrm{~min}$ resulted in the precipitation processes ending with $\delta^{\prime}$ particles.

A key strength of the demonstrated APT based approach is the ability to identify and quantify the fine-scale segregation effects of dilute solutes in $\mathrm{Al}$ alloys; this supports the understanding of precipitation behavior in this important technical material.

\section{Acknowledgements}

Prof. Talaat Al-Kassab (Associate Professor of material science and engineering, King Abdullah University of Science and Technology), Prof. Ferdinand Haider (professor at University Augsburg, Inst. f. Physics) and Pascal Niebecker (PhD student at Technische Universität München) are gratefully acknowledged. M. Khushaim gratefully acknowledges financial support provided through King Abdullah University of Science and 
Technology (KAUST) base-line funding program.

\section{References}

[1] Polmear, I.J. (2006) Light Alloys from Traditional Alloys to Nanocrystals. Elsevier, Amsterdam.

[2] Totten, G.E. and MacKenzie, D.S. (2003) Physical Metallurgy and Processes. In: Handbook in Aluminum, M. Dekker, New York.

[3] Hono, K. (1999) Atom Probe Microanalysis and Nanoscale Microstructures in Metallic Materiales. Acta Material, 47, 3172. http://dx.doi.org/10.1016/S1359-6454(99)00175-5

[4] Gayle, F.W. and Goodway, M. (1994) Precipitation Hardening in the First Aerospace Aluminum Alloy: The Wright Flyer Crankcase. Science, 266, 1015-1017. http://dx.doi.org/10.1126/science.266.5187.1015

[5] Polmear, I.J. (2004) Aluminium Alloys-A Century of Age Hardening. Materials Forum, 28.

[6] Konno, T.J., Hiraga, K. and Kawasaki, M. (2001) Guinier-Preston (GP) Zone Revisited: Atomic Level Observation by HAADF-TEM Technique. Scripta Materialia, 44, 2303-2307. http://dx.doi.org/10.1016/S1359-6462(01)00909-5

[7] Gerold, V. (1988) On the Structures of Guinier-Preston Zones in Al \{Single Bond\} Cu Alloys Introductory Paper. Scripta Metallurgica, 22, 927-932. http://dx.doi.org/10.1016/S0036-9748(88)80077-2

[8] Silcock, J.M. (1956) The Structure in Aluminium-Copper Alloys. Acta Crystallographica, 9, 680. http://dx.doi.org/10.1107/S0365110X56001820

[9] Hono, K., Babu, S.S., Hiraga, K., Okano, R. and Sakurai, T. (1992) Atom Probe Study of Early Stage Phase Decomposition in an Al-7.8 at.\% Li Alloy. Acta Metallurgica et Materialia, 40, 3027-3034. http://dx.doi.org/10.1016/0956-7151(92)90466-R

[10] Noble, B. and Thompson, G.E. (1971) Precipitation Characteristics of Aluminium-Lithium Alloys. Metal Science, 5, 114-120. http://dx.doi.org/10.1179/030634571790439333

[11] Baumann, S.F. and Williams, D.B. (1985) Effects of Capillarity and Coherency on $\delta\left(\mathrm{Al}_{3} \mathrm{Li}\right)$ Precipitation in Dilute Al-Li Alloys at Low Undercoolings. Acta Metallurgica, 33, 10691078. http://dx.doi.org/10.1016/0001-6160(85)90200-7

[12] Khachaturyan, A.G., Lindsey, T.E. and Morris, J.J.W. (1988) Theoretical Investigation of the Precipitation of in AI-Li. Metallurgical Transactions A, 19, 249.

http://dx.doi.org/10.1007/BF02652533

[13] Schmitz, G., Hono, K. and Haasen, P. (1994) High Resolution Electron Microscopy of the Early Decomposition Stage of Al-Li Alloys. Acta Metallurgica et Materialia, 42, 201-211. http://dx.doi.org/10.1016/0956-7151(94)90063-9

[14] Al-Kassab, T., Menand, A., Chambreland, S. and Hassen, P. (1991) The Early Stages of Decomposition of Al-Li Alloys. Surface Science, 266, 333-336. http://dx.doi.org/10.1016/0039-6028(92)91042-A

[15] Effenberg, G. and Ilyenko, S. (2007) Al-Cu-Li (Aluminium-Copper-Lithium). In: NonFerrous Metal Systems. Part 2, Springer, Berlin Heidelberg, 1-42.

[16] Hardy, H.K. and Silcock, J.M. (1955-1956) The Phase Sections at 500 and $350^{\circ} \mathrm{C}$ of $\mathrm{Al}$ Rich Al-Cu-Li Alloys. Journal of the Institute of Metals, 84, 423-428.

[17] Dorward, R.C. (1988) Solidus and Solvus Isotherms for Quaternary Al-Li-Cu-Mg Alloys. Metallurgical Transactions A, 19, 1631-1634. http://dx.doi.org/10.1007/BF02674041

[18] Moser, Z., Gasior, W., Onderka, B., Sommer, F. and Kim, Z. (2002) Al-Cu-Li System Elec- 
tromotive Force and Calorimetric Studies-Phase Diagram Calculations of the Al-Rich Part. Journal of Phase Equilibria, 23, 127-133. http://dx.doi.org/10.1361/1054971023604134

[19] Wang, K. and Garoche, P. (1997) Phason-Strain-Field Influences on Low-Temperature Specific Heat in Icosahedral Quasicrystals Al-Li-Cu and Al-Fe-Cu. Physical Review B, 55, 250-258. http://dx.doi.org/10.1103/PhysRevB.55.250

[20] Dubost, B., Colinet, C. and Ansara, I. (1989) An Experimental and Thermodynamic Study of the Al-Cu-Li Equilibrium Phase Diagram. 5th International Aluminium-Lithium Conference, Williamsburg, 27-31 March 1989, 28-31.

[21] Noble, B. and Thompson, G.E. (1972) Precipitation in Aluminium-Copper-Lithium Alloys. Materials Science, 6, 167-174.

[22] Van Smaalen, S., Meetsma, A., Deboer, J.L. and Bronsveld, P.M. (1990) Refinement of the Crystal Structure of Hexagonal $\mathrm{Al}_{2} \mathrm{CuLi}$. Solid State Chemistry, 85, 293-298. http://dx.doi.org/10.1016/S0022-4596(05)80086-6

[23] Dlubek, G., Krause, S., Krause, H., Berasina, A.L., Mikhalenkav, V.S. and Chuistov, K.V. (1992) Positron Studies of Precipitation Phenomena in Al-Li and in Al-LI-X (X=Cu, Mg or Sc) Alloys. Journal of physics: Condensed Matter, 4, 6317-6328. http://dx.doi.org/10.1088/0953-8984/4/29/015

[24] Hornbogen, E. (2000) Formation of nm-Size Dispersoids from Supersaturated Solid Solutions of Aluminium. Material Science Forum, 331-337, 879-888. http://dx.doi.org/10.4028/www.scientific.net/MSF.331-337.879

[25] Hellman, O.C., Du Rivage, J.B. and Seidman, D.N. (2003) Efficient Sampling for Three-Dimensional Atom Probe Microscopy Data. Ultramicroscopy, 95, 199-205.

http://dx.doi.org/10.1016/S0304-3991(02)00317-0

[26] Vaumousse, D., Cerezo, A. and Warren, P.J. (2003) A Procedure for Quantification of Precipitate Microstructures from Three-Dimensional Atom Probe Data. Ultramicroscopy, 95, 215-221. http://dx.doi.org/10.1016/S0304-3991(02)00319-4

[27] Gault, B., Moody, M.P., Cairney, J.M. and Ringer, R. (2012) Atom Probe Microscopy. Springer Series in Materials Science, Springer, New York.

http://dx.doi.org/10.1007/978-1-4614-3436-8

[28] Moody, M.P., Stephenson, L.T., Geguerra, A.V. and Ringer, S.P. (2008) Quantitative Binomial Distribution Analyses of Nanoscale Like-Solute Atom Clustering and Segregation in Atom Probe Tomography Data. Microscopy Research and Technique, 71, 542-550. http://dx.doi.org/10.1002/jemt.20582

[29] Ünlü, N., Gable, B.M., Shiflet, G.J. and Starke Jr., E.A. (2003) The Effect of Cold Work on the Precipitation of $\Omega$ and $\theta$ in a Ternary Al-Cu-Mg Alloy. Metallurgical and Materials Transactions A, 34, 2757-2769. http://dx.doi.org/10.1007/s11661-003-0177-y

[30] Murch, G.E., Bruff, C.M. and Mehrer, H. (1990) Chemical Diffusion Tables. Part of Landolt-Börnstein-Group III Condensed Matter, Springer Materials-The Landolt-Börnstein Database, Berlin.

[31] Silcock, J.M., Heal, T.J. and Hardy, H.K. (1953-1954) Structural Ageing Characteristics of Aluminum-Copper Alloys. Journal of the Institute of Metals, 82, 239-248.

[32] Boyd, J.D. and Nicholson, R.B.M. (1971) The Coarsening Behaviour of and Precipitates in Two Al-Cu Alloys. Acta Metallurgica, 19, 1379-1391. http://dx.doi.org/10.1016/0001-6160(71)90076-9

[33] Ringer, S.P. and Hono, K. (2000) Microstructural Evolution and Age Hardening in Aluminium Alloys: Atom Probe Field-Ion Microscopy and Transmission Electron Microscopy Studies. Materials Characterization, 44, 101-131. 
http://dx.doi.org/10.1016/S1044-5803(99)00051-0

[34] Ceresaraa, S., Giardaa, A. and Sanchéza, A. (1977) Annealing of Vacancies and Ageing in Al-Li Alloys. Philosophical Magazine, 35, 97-110. http://dx.doi.org/10.1080/14786437708235975

[35] Kulkarni, G.J., Banerjee, D. and Ramachandran, T.R. (1989) Physical Metallurgy of Aluminum-Lithium Alloys. Bulletin of Materials Science, 12, 325-340.

http://dx.doi.org/10.1007/BF02747140

Submit or recommend next manuscript to SCIRP and we will provide best service for you:

Accepting pre-submission inquiries through Email, Facebook, LinkedIn, Twitter, etc.

A wide selection of journals (inclusive of 9 subjects, more than 200 journals)

Providing 24-hour high-quality service

User-friendly online submission system

Fair and swift peer-review system

Efficient typesetting and proofreading procedure

Display of the result of downloads and visits, as well as the number of cited articles

Maximum dissemination of your research work

Submit your manuscript at: http://papersubmission.scirp.org/

Or contact ojmetal@scirp.org 